\title{
AUTOLOGOUS DERMAL FIBROBLAST INJECTIONS SLOW \\ ATRIOVENTRICULAR CONDUCTION AND VENTRICULAR RATE IN \\ ATRIAL FIBRILLATION IN SWINE
}

Authors: Fernando Tondato, MD, PhD ${ }^{*}$; Hong Zeng, MD*; Traci Goodchild, PhD*;

Nicolas Chronos, MD, FACC*; Nicholas S. Peters, MD $^{\S}$

From $\S$ Myocardial Function Section, Imperial College \& Imperial NHS Trust, London, United Kingdom

*Saint Joseph's Translational Research Institute/ Saint Joseph's Hospital of Atlanta, Atlanta, GA, USA, 30342;

Total word count: 4,603 words (abstract $=250$ words)

Running Title: Fibroblasts Slow Ventricular Rate in AF

Correspondence to:

Nicholas S. Peters

Email:‥peters@imperial.ac.uk

Address:

St Marys Hospital, Imperial College, Dept of Cardiology

ICTEM 4th Floor

Hammersmith Campus, Du Cane Rd

London, England, W12 0NN

United Kingdom

Phone: +44-207-594-1880

Disclosures: This study was supported by a research grants from CardioPolymers, Inc. (formerly Symphony Medical), Inc., and the British Heart Foundation (RG/10/11/28457), but all the contents of the manuscript are solely the responsibility of the authors. The authors acknowledge NIHR Biomedical Research Centre (UK) funding. 


\begin{abstract}
Background: Non-pharmacological ventricular rate control in atrial fibrillation (AF) without producing atrioventricular block (AVB) remains a clinical challenge. We investigated the hypothesis that autologous dermal fibroblast (ADF) injection into the AV nodal area (AVNA) would reduce ventricular response during AF without causing AVB.
\end{abstract}

Methods and Results: Fourteen pigs underwent electrophysiology study before, immediately and 28 days after $\sim 200$ million cultured ADFs $(n=8)$ or saline $(n=6)$ were injected under electroanatomical guidance in the AVNA, with continuous 28-day ECG recording. In the $\mathrm{ADF}$ group at 28 days post-injection there were prolongations of $\mathrm{PR}$ interval (after vs. before: $130 \pm 13 \mathrm{msec}$ vs. $113 \pm 14 \mathrm{msec}, P=0.04$ ), of $\mathrm{AH}$ interval during both sinus rhythm $(92 \pm 13 \mathrm{msec}$ vs. $76.8 \pm 8 \mathrm{msec}, P<0.01)$ and atrial pacing at $400 \mathrm{~ms}$ $102 \pm 13 \mathrm{msec}$ vs. $91 \pm 9 \mathrm{msec}, P<0.01$ ), and of AV node Wenckebach cycle length $(230 \pm 19 \mathrm{mec}$ vs. $213 \pm 24 \mathrm{msec}, P<0.01)$, with no changes in the control group. The RR interval during induced AF 28 days after injections was $24 \%$ longer in ADF-treated group compared to controls $(488 \pm 120 \mathrm{msec}$ vs. $386 \pm 116 \mathrm{msec}, P<0.001)$. Histological analysis revealed presence of ADF-labeled cells in the AVNA at 28 days. Transient accelerated junctional rhythm during injections, and transient nocturnal Mobitz I AV conduction occurred early post-injection in both groups.

Conclusion: Cells survived for 4 weeks and significantly slowed AV conduction and ventricular rate in acutely induced AF. Critically, despite a large number of injections in the AVNA and marked effects on AV conduction, AVB did not occur. Further studies are necessary to determine the clinical feasibility and safety of this strategy for ventricular rate control in AF. 


\section{INTRODUCTION:}

Drug treatment to maintain long-term sinus rhythm or achieve ventricular rate control in atrial fibrillation (AF) is limited by lack of efficacy or intolerance of side effects ${ }^{1,2}$. Nonpharmacological approaches ${ }^{3,4}$ such as pulmonary vein isolation are effective but this is not practicable or appropriate for all patients. Several randomized controlled clinical trials ${ }^{5-7}$ have shown that ventricular rate control in patients with atrial fibrillation can be an effective therapeutic approach, with outcomes in some patient groups that are comparable to strategies for maintenance of sinus rhythm. Rate control in AF therefore remains an appropriate and common palliative strategy, and for symptomatic patients when all pharmacological and other non-pharmacological approaches have failed, AV node ablation is a well-established and widely practiced technique ${ }^{8}$, achieving control of symptoms in the majority of patients, but requires permanent pacemaker implantation. Previously, various strategic approaches to attempt AV node modification to control rather than abolish AV conduction have all been shown to have prohibitive risk of complete AV block, ${ }^{9,10}$ and are therefore rarely attempted in current clinical practice.

Among the advances in the area of cell therapy ${ }^{11-14}$, multiple cell types have been used for myocardial repair and regeneration ${ }^{15-18}$ including restoration of conduction in experimental models ${ }^{19}, 20$. Cellular therapies have the potential to either enhance or block electrical conduction of the heart, ${ }^{21,22}$ and although dermal fibroblasts injected in the atrioventricular node area have been shown to modify conduction velocity, ${ }^{21}$ the clinical therapeutic goal in AF is not that of slowing AV nodal conduction, but of controlling ventricular response rate. The aim of this study was to address the hypothesis that injections of adult autologous dermal fibroblasts (ADF) in the AV node area would 
inhibit AV node conduction, resulting in control of ventricular response during $\mathrm{AF}$ without inducing complete AV block or evidence of fibrotic changes in the lung.

\section{METHODS:}

\section{Animal Preparation:}

The protocol was consistent with federal guidelines for the care and use of laboratory animals and was approved by the Institutional Animal Care and Use Committee of the Saint Joseph's Translational Research Institute. Fourteen juvenile farm pigs weighing $48.7 \pm 10.1 \mathrm{Kg}$ were enrolled into the study. Anesthesia was induced by an intramuscular injection of a combination of 2 to $4 \mathrm{mg} / \mathrm{Kg}$ of telazol, $4 \mathrm{mg} / \mathrm{Kg}$ of ketamine and $2 \mathrm{mg} / \mathrm{Kg}$ of xylazine, followed by intubation and general anesthesia induced and maintained using inhalant isoflurane $\left(\sim 1.5-2.5 \%\right.$ in $\left.\mathrm{O}_{2}\right)$.

\section{Autologous Dermal Fibroblast Preparation}

The groin regions were shaved, scrubbed and draped. A $6 \times 2 \mathrm{~cm}$ sample of skin was harvested. The tissue was minced and digested in $0.25 \%$ Trypsin-EDTA for $1 \mathrm{~h}$ at $37^{\circ} \mathrm{C}$. Dulbecco's modified eagles medium (DMEM) containing 15\% fetal bovine serum (FBS) was added then digest was filtered through $100 \mu \mathrm{m}$ strainer. Cells were washed twice with phosphate buffered saline (PBS) and the final cell pellet was re-suspended in DMEM with $10 \%$ FBS with Penicillin/Streptomycin (1\%) and placed in culture at $37^{\circ} \mathrm{C}$ with $5 \%$ $\mathrm{CO}_{2}$. Fibroblasts were grown to $80 \%$ confluence then passaged (22). Passage 2-4 was used for cell injections. Prior to injection, fibroblasts were labeled with CM-DiI $2 \mu \mathrm{l} / \mathrm{ml}$ (Invitrogen, Carlsbad, CA). Cell number and viability was determined using the Trypan blue dye exclusion method before injection. 


\section{Electrophysiologic Study:}

Standard quadripolar EP catheters (Cordis, 6F) were inserted through the right and/or left femoral veins and advanced to the right atrial (RA), right ventricular apex (RVA), coronary sinus and His bundle positions under fluoroscopic guidance. The electrodes were connected to an EP-3 WorkMate ${ }^{\circledR}$ system (EP MedSystems, Inc., Mount Arlington, NJ, U.S.A.), and standard electrophysiological study with programmed stimulation was performed to determine $\mathrm{PR}, \mathrm{AH}$ and $\mathrm{HV}$ intervals, AV node Wenckebach and RR intervals during AF induced by rapid RA pacing. PR interval was determined as the time interval between the P wave onset and QRS onset on the surface ECG. AH interval was determined as the time interval between the initial atrial deflection to the initial $\mathrm{H}$ deflection recorded in the His bundle electrogram, and was measured during sinus rhythm and atrial pacing at 400,500 , and $600 \mathrm{msec}$ drive cycle length by using $2.0 \mathrm{msec}$ square pulses at twice diastolic pacing threshold. HV interval was determined as the time interval between the initial $\mathrm{H}$ deflection recorded in the His bundle electrogram and the earliest deflection of the QRS complex on the surface ECG. The AV node Wenckebach cycle length was determined by decremental pacing from RA (progressive reduction of pacing cycle length, translating into faster pacing rates) at twice the diastolic pacing threshold until anterograde type I second-degree AV block (Wenckebach) occurred. The above EP measurements were performed before injections, immediately after injections and at post injection time point of 28 days. AF was induced at follow-up ( 28 days) by RA pacing at a cycle length of $100 \mathrm{msec}$ at $2.0 \mathrm{msec}$ square pulses and current $10.0 \mathrm{~mA}$, and sustained for a variable period after cessation of pacing, during which ten consecutive RR intervals during AF were used to calculate ventricular rate. 


\section{Autologous Dermal Fibroblast Injections:}

Eight pigs received cell injections and six pigs received saline solution as a control.

An RA geometry was made with a $4 \mathrm{~mm}$ tip eletroanatomical mapping catheter (Biosense Webster, Diamond Bar, CA, U.S.A.) with a filling threshold of $15 \mathrm{~mm}$, marking the positions of the His bundle and the ostium of coronary sinus (CARTO ${ }^{\mathrm{TM}} 4.0$ system, Biosense, Diamond Bar, CA, U.S.A.). A Myostar catheter (Biosense Webster, Diamond Bar, CA, U.S.A.) - a deflectable CARTO-compatible injection catheter, was then used for marking the locations of the multiple injections on the RA geometry. The Myostar catheter has an adjustable needle depth. Preliminary bench testing had determined the ideal cell concentration to maximize viability and the optimal volume of each injection that could be retained in an ex-vivo myocardial preparation. Based on these preliminary studies (data not shown), the yield from the fibroblast cell cultures was diluted to a volume of $50 \mathrm{ml}$ for an injection volume of $0.8 \mathrm{ml}$ delivered by indeflator pressurized to 20 atm, resulting in $\sim 60$ injections per case. The Myostar is deflectable and designed to provide support for needle penetration on deployment, and preliminary in vivo studies using radiopaque contrast in the injectate confirmed tissue penetration and contrast retention, and $2 \mathrm{~mm}$ as being an optimal needle-depth setting for the purposes of injection in the region of the triangle of Koch in this study (data not shown).

Guided by the RA geometry, multiple $0.8 \mathrm{ml}$ injections of a total of $50 \mathrm{ml}$ of ADF or saline were delivered along the slow and fast pathway regions around the AV node. Although initial injections focused on the inputs to AV node, the large number of injections extended to the region of confluence of slow and fast pathways, and therefore the region of the compact $\mathrm{AV}$ node, which was not deliberately avoided. In each 
position, the needle was deployed and the interval between each indeflator injection was approximately 60 seconds. The sites of injections were tagged on the CARTO map (Figure 1). After injections, a trans-thoracic echocardiogram (Acuson, Siemens, Mountain view, CA, U.S.A.) was performed to exclude complications and evaluate atrial and ventricular form and function.

Preliminary bench testing had determined the ideal cell concentration to maximize viability and the optimal volume of each injection that could be retained in an ex-vivo myocardial preparation. Based on these preliminary studies (data not shown), the yield from the fibroblast cell cultures was diluted to a volume of $50 \mathrm{ml}$ for an injection volume of $0.8 \mathrm{ml}$ delivered by indeflator pressurized to 20 atm, resulting in $\sim 60$ injections per case. The Myostar is deflectable and designed to provide support for needle penetration on deployment, and preliminary in vivo studies using radiopaque contrast in the injectate confirmed tissue penetration and contrast retention, and $2 \mathrm{~mm}$ as being an optimal needledepth setting for the purposes of injection in the region of the triangle of Koch in this study (data not shown).

\section{Transmitter Implant and ECG Monitoring:}

After completing injections and EP evaluation, animals underwent implantation of a telemetry transmitter (TA10CTA-D70, DSI Systems ${ }^{\mathrm{TM}}$, Data Sciences International Inc, St. Paul, MN, U.S.A.) in the subcutaneous space of the abdomen for continuous telemetry ECG monitoring and recording over the ensuing 4 weeks. On full disclosure and 
examination of all ECG recording, the PR interval at its longest and any changes indicative of AV block or other cardiac arrhythmia during each period of 24 hours were reported.

\section{Restudy and Histology:}

At 28 days after injections, CARTO mapping and EP studies were repeated. Animals were euthanized; the heart and the lungs were harvested and the injected area corresponding to Koch's triangle encompassing the AV node region was dissected for histological analysis (Figure 2). Samples were divided into 3 pieces and each piece was further divided into 3 sections where one was fixed in $10 \%$ buffered formalin, embedded in paraffin, $5 \mu \mathrm{m}$ sections cut and stained with hematoxylin-eosin for assessment of overall cellularity and Verhoeff-Masson for collagen deposition. The other two sections were processed for frozen sectioning to identify CM- DiI positively labeled ADF. Frozen sections were cut and counterstained with 4', 6-diamidino-2-phenylindole (DAPI, Sigma, St. Louis, MO) to highlight cell nuclei. Images were acquired using epifluorescence microscopy (Nikon Eclipse E400, Japan).

\section{Data analysis:}

Data are expressed as mean \pm standard deviation. Student's t-tests were performed in order to compare continuous variables with normal distribution. Paired t-tests were used to compare repeated measurements in the same group. The non-parametric test of MannWhitney was used for comparison between those samples without a normal distribution. A probability value of $\leq 0.05$ was considered significant. For multiple repeated-measures comparisons, 2-way ANOVA was used, using significant $\mathrm{p}$ value $<0.05$. 


\section{RESULTS:}

\section{Cell Culture and Injection}

A total of $1.9 \pm 0.6 \times 10^{8}$ cells were obtained from each culture (Figure 3 ). The average culture time was $27 \pm 10$ days. The cell viability after CM-DiI labeling and immediately before injection was $96 \pm 5 \%$.

Injections were performed without apparent adverse effect. The number of injections was comparable between both groups (cell group $(n=8)$ : $66 \pm 20$; control group $(n=6)$ : $59 \pm 17$; $p=0.52)$.

\section{Electrophysiologic study:}

Brief episodes of junctional rhythm with normal QRS morphology during and immediately following injections were common in both groups, and resolved with return to sinus rhythm in the first few hours post-procedure. For this reason, PR and AH interval measurements could not be consistently or reliably measured immediately after injections. PR and $\mathrm{AH}$ intervals in sinus rhythm were comparable between groups at baseline. A summary of measured intervals is shown in Table 1.

During sinus rhythm at 28 days after injection there was significant prolongation of both the PR $(130 \pm 13 \mathrm{msec}$ vs. $113 \pm 14 \mathrm{msec}, p=0.04)$ and $\mathrm{AH}(92 \pm 13 \mathrm{msec}$ vs. $80 \pm 7 \mathrm{msec}$, $p=0.016)$ intervals compared to baseline in the ADF-treated group, but not in the control group (Table 1). The mean change in PR and AH intervals (ADF-treated vs control) were $+17 \mathrm{~ms}$ vs $+9 \mathrm{~ms}(\mathrm{p}=0.04)$, and $+12 \mathrm{~ms}$ vs $+1 \mathrm{~ms}(\mathrm{p}=0.01)$ respectively. 
During fixed atrial pacing at 600,500 and $400 \mathrm{msec}$ at 28 days, AH intervals were significantly increased at all cycle lengths in the ADF group compared to baseline in the ADF-treated group but not in the control group These findings translated into significant differences in AH interval between ADF-treated and control groups at all paced cycle lengths (Table 2).

The ANOVA analysis showed that there were no significant variations in the measured HV interval at baseline, immediately post injection and at follow-up (Table 1), neither in the cell group $(\mathrm{p}=0.37)$, nor in the control group $(\mathrm{p}=0.47)$

The AV node Wenckebach cycle length showed no difference between groups either at baseline $(210 \pm 32 \mathrm{msec}$ in control group, and $213 \pm 24 \mathrm{msec}$ in cell group, $p=0.87)$, and prolonged significantly at 28 days only in the ADF-treated group compared to baseline (230 $\pm 19 \mathrm{mec}$ vs. $213 \pm 24 \mathrm{msec}, p=0.009)$.

\section{Ventricular rate during $\mathrm{AF}$}

At 28 days after injection, the mean RR interval during acutely induced AF was $\sim 100 \mathrm{msec}$ longer in the ADF-treated group compared to controls $(488 \pm 120 \mathrm{msec}$ vs. $386 \pm 116 \mathrm{msec}, p<0.001$ ), with no change in the control group.

\section{Continuous ECG Telemetry}

Real-time ECG monitoring during the 28 days of observation showed PR interval prolongation during the first 5-7 days after injection in both groups, then progressively returning to baseline levels in the control group. The ADF group, however, presented a partial return of PR interval but not back to baseline levels and remained steadily elevated for the ensuing period of observation (see Figure 4). In one animal in ADF-treated group, 
two isolated episodes of nocturnal second-degree AV block occurred on the second and third days of observation (Figure 5). Neither late complete AV block nor change in HV intervals occurred in either group.

\section{Necropsy and Histological Findings:}

No evidence of perforation, thrombosis or pericarditis was noted during macroscopic analysis. Under light microscope, small isolated concentrations of scant mononuclear cells were found in the perinodal myocardium in the ADF-treated group, probably representing mild localized inflammation, (Figure 6) with no evidence of any major inflammatory response. Under epifluorescent microscopy, only in the ADF group, CMDiI-labeled cells were identified (Figure 7). The presence of CM-DiI at the membrane surface concordant with the DAPI counterstaining in the nuclei confirms cell viability at the time of sacrifice. Extensive examination of the lungs showed no macroscopic or microscopic abnormalities.

\section{DISCUSSION:}

The findings of this study are that ADFs can be safely injected into the AV nodal region, resulting in slowing of $\mathrm{AV}$ nodal conduction and of the ventricular response rate in acutely induced AF in pigs. Importantly, despite a deliberately large number of injections, no animal developed complete AV block in the first 28 days, and only one animal had two brief episodes of transient nocturnal second degree AV block (narrow QRS) during the first two days after injection. No attempt was made to avoid the compact AV node, and that some of the injections will have been directly in to this region was 
evident from the acute detectable effects on AV nodal function (prolongation of $\mathrm{AH}$ and PR intervals) in the absence of AV block up to 28 days, suggests a margin of safety that is unique among all previous attempted strategies for AV nodal modification and a highly promising proof of concept.

Transient junctional rhythm and prolongation of the PR interval during injections were both observed, but always settled with return to sinus rhythm and normalization of the PR interval within a few hours after completion of the injections. The frequency, timing and consistency of these transient changes in rhythm in both groups would implicate mechanical trauma of the injection procedure and not the later biological response to ADF transplantation.

While the initial changes can be explained by a simple mechanical effect, the late changes seen only in the ADF group - the prolongation of the $\mathrm{AH}$ interval, the Wenckebach cycle length and, most importantly with respect to potential clinical applicability, prolongation of the mean R-R interval in acutely induced AF, result from the late biological effect of the injected ADF cells.

Dermal fibroblasts are mesenchymal cells that are readily isolated and cultured in the laboratory and play an important role in tissue engineering and regeneration, including the treatment of burns, chronic venous ulcers and several other clinical applications in dermatology and plastic surgery ${ }^{23-27}$. Although previous studies have reported the effects of ADF on myocardial conduction, including the AV node and focusing principally on conduction velocity (20-27), no previous studies have addressed the critical safety concern of high-grade AV block excluded by the extended and continuous rhythm 
monitoring in the present study. The putative mechanisms for the effect of the transplanted ADFs in retarding AV conduction include collagenous interruption of the myocardial syncytium and cell separation, and myocyte-fibroblast gap-junctional coupling providing an alternative sink for charge transfer between cardiac myocytes ${ }^{28}$. We have shown previously that injection of autologous dermal fibroblasts in chronic myocardial infarction can potentially lead to stabilization of arrhythmogenic burden in a swine model, preventing development of both induced and spontaneous ventricular arrhythmias (29). Kizana et $\mathrm{al}^{29}$ reported that fibroblasts can be genetically modified to produce excitable cells capable of electrical coupling, with additional potential for treating cardiac conduction defects.

In the present study, histological examination showed that after 4 weeks there was no significant inflammatory or major fibrotic response in either the perinodal myocardium or the lungs, which will have received significant ADF overspill from injections, indicating that despite a different tissue of origin, autologous cells for ventricular rate control in atrial fibrillation remains a realistic proposition requiring further investigation.

\section{Clinical application}

Clinical trials continue to address the question of rate versus rhythm control in atrial fibrillation, and some studies indicate that in certain populations of patients, a rate control strategy may be preferable. Although the strategy of rhythm control has benefited from ablation and novel anti-arrhythmic drugs, therapeutic options in rate control have remained largely unchanged for decades and expose patients to drugs frequently with 
limited efficacy and side effects or the need for permanent ventricular pacing after AV node ablation.

Specifically, attempts at AV nodal modification, such as with selective RF, cryo-, or other destructive ablation with the intent to avoid complete abolition of AV nodal conduction and retain normal ventricular activation sequence, have proven unsuccessful because of an unacceptable incidence of AV block. Although of limited clinical utility as a measure of efficacy, when assessing safety the PR and AH intervals were very important to measure at the time of injection because this study was designed specifically to give a very large number of injections in and around the AVN in an attempt to cause AV block - failure to achieve which, coupled with the early modest changes in AH and $\mathrm{PR}$, is reassuring of a much wider margin of safety of critical importance to this proof of concept compared with previous interventions to modify AVN, including RF and Cryo. Autologous fibroblast injection that can safely be delivered transvenously to slow ventricular rate in $\mathrm{AF}$ as an alternative to long term drug treatment, is a compelling treatment strategy of potential high impact requiring further investigation.

Before progressing to clinical use in humans, further studies will be necessary to determine the ideal cell concentration, volume and total number of cells or injections per patient in order to achieve maximum efficacy, without compromising the safety of the procedure. 


\section{Limitations}

Despite the small numbers of animals, the lasting and beneficial effects on $\mathrm{AV}$ conduction indicate a robust treatment effect for the 4 weeks of follow up. Further studies will be required to investigate more long-term effects in progressing towards clinical application and to better clarify the specific mechanism involved in the atrioventricular conduction delay induced by $\mathrm{ADF}$. The atrial fibrillation in this study was acutely induced episodes, and may differ from more naturally occurring AF.

The present study did not evaluate the effect of isoproterenol challenge acutely after injections because the expected effects of this intervention on AVN conduction, as proved to be correct, took days to evolve, and procedural testing would not therefore have been informative. In fact, acutely the main question was that of safety (AV block) rather than efficacy, and to have given isoproterenol may potentially have masked this. In follow up, we considered the telemetered ventricular rate monitoring that was performed in this study to be the most informative measure.

\section{Conclusions}

Transplantation of ADFs in the AV node area in pigs is feasible, safe and slows ventricular rate in acutely induced AF. Despite a large number of injections, complete AV block did not occur. These results encourage further investigation of a novel strategy for controlling ventricular rate in $\mathrm{AF}$. 


\section{Acknowledgment:}

The authors acknowledge British Heart Foundation Centre of Research Excellence and Programme Grant RG/10/11/28457, NIHR Biomedical Research Centre, and the great contribution of our colleague Dr. Keith Robinson, sadly deceased.

\section{Conflict of Interest:}

Fernando Tondato, MD, PhD: None;

Hong Zeng, MD: None;

Traci Goodchild, PhD: None;

Nicolas Chronos, MD, FACC: None;

Nicholas S. Peters, MD: None

\section{REFERENCES:}

1. Janko S, Dorwarth U, Hoffmann E. Pharmacotherapy of atrial fibrillation: An old option with new possibilities. Expert opinion on pharmacotherapy. 2008;9:913925

2. Lip GY, Tse HF. Management of atrial fibrillation. Lancet. 2007;370:604-618

3. Cleland JG, Coletta AP, Buga L, Ahmed D, Clark AL. Clinical trials update from the american college of cardiology meeting 2010: Dose, aspire, connect, stich, stop-af, cabana, race ii, everest ii, accord, and navigator. Eur J Heart Fail. 2010;12:623-629

4. Calkins H, Kuck KH, Cappato R, Brugada J, Camm AJ, Chen SA, Crijns HJ, Damiano RJ, Jr., Davies DW, DiMarco J, Edgerton J, Ellenbogen K, Ezekowitz MD, Haines DE, Haissaguerre M, Hindricks G, Iesaka Y, Jackman W, Jalife J, Jais P, Kalman J, Keane D, Kim YH, Kirchhof P, Klein G, Kottkamp H, Kumagai K, Lindsay BD, Mansour M, Marchlinski FE, McCarthy PM, Mont JL, Morady F, Nademanee K, Nakagawa H, Natale A, Nattel S, Packer DL, Pappone C, Prystowsky E, Raviele A, Reddy V, Ruskin JN, Shemin RJ, Tsao HM, Wilber D. $2012 \mathrm{hrs} / \mathrm{ehra} /$ ecas expert consensus statement on catheter and surgical ablation of atrial fibrillation: Recommendations for patient selection, procedural techniques, patient management and follow-up, definitions, endpoints, and research trial design: A report of the heart rhythm society (hrs) task force on catheter and surgical ablation of atrial fibrillation. Developed in partnership with the european 
heart rhythm association (ehra), a registered branch of the european society of cardiology (esc) and the european cardiac arrhythmia society (ecas); and in collaboration with the american college of cardiology (acc), american heart association (aha), the asia pacific heart rhythm society (aphrs), and the society of thoracic surgeons (sts). Endorsed by the governing bodies of the american college of cardiology foundation, the american heart association, the european cardiac arrhythmia society, the european heart rhythm association, the society of thoracic surgeons, the asia pacific heart rhythm society, and the heart rhythm society. Heart rhythm : the official journal of the Heart Rhythm Society. 2012;9:632-696 e621

5. Roy D, Talajic M, Nattel S, Wyse DG, Dorian P, Lee KL, Bourassa MG, Arnold JM, Buxton AE, Camm AJ, Connolly SJ, Dubuc M, Ducharme A, Guerra PG, Hohnloser SH, Lambert J, Le Heuzey JY, O'Hara G, Pedersen OD, Rouleau JL, Singh BN, Stevenson LW, Stevenson WG, Thibault B, Waldo AL. Rhythm control versus rate control for atrial fibrillation and heart failure. The New England journal of medicine. 2008;358:2667-2677

6. Van Gelder IC, Hagens VE, Bosker HA, Kingma JH, Kamp O, Kingma T, Said SA, Darmanata JI, Timmermans AJ, Tijssen JG, Crijns HJ. A comparison of rate control and rhythm control in patients with recurrent persistent atrial fibrillation. The New England journal of medicine. 2002;347:1834-1840

7. Wyse DG, Waldo AL, DiMarco JP, Domanski MJ, Rosenberg Y, Schron EB, Kellen JC, Greene HL, Mickel MC, Dalquist JE, Corley SD. A comparison of rate control and rhythm control in patients with atrial fibrillation. The New England journal of medicine. 2002;347:1825-1833

8. Lim KT, Davis MJ, Powell A, Arnolda L, Moulden K, Bulsara M, Weerasooriya R. Ablate and pace strategy for atrial fibrillation: Long-term outcome of aircraft trial. Europace. 2007;9:498-505

9. Feld GK. Atrioventricular node modification and ablation for ventricular rate control in atrial fibrillation. Heart Rhythm. 2007;4:S80-83

10. Zhang Y, Mazgalev TN. Ventricular rate control during atrial fibrillation and av node modifications: Past, present, and future. Pacing Clin Electrophysiol. 2004;27:382-393

11. Fine GC, Liao R, Sohn RL. Cell therapy for cardiac repair. Panminerva medica. 2008;50:129-137

12. Srivastava D, Ivey KN. Potential of stem-cell-based therapies for heart disease. Nature. 2006;441:1097-1099

13. Wollert KC. Cell therapy for acute myocardial infarction. Current opinion in pharmacology. 2008;8:202-210

14. Yamahara K, Nagaya N. Stem cell implantation for myocardial disorders. Current drug delivery. 2008;5:224-229

15. Clavel C, Verfaillie CM. Bone-marrow-derived cells and heart repair. Current opinion in organ transplantation. 2008;13:36-43

16. Evans SM, Mummery C, Doevendans PA. Progenitor cells for cardiac repair. Seminars in cell \& developmental biology. 2007;18:153-160

17. Roccio M, Goumans MJ, Sluijter JP, Doevendans PA. Stem cell sources for cardiac regeneration. Panminerva medica. 2008;50:19-30 
18. Siminiak T, Kalmucki P, Kurpisz M. Autologous skeletal myoblasts for myocardial regeneration. Journal of interventional cardiology. 2004;17:357-365

19. Beeres SL, Atsma DE, van der Laarse A, Pijnappels DA, van Tuyn J, Fibbe WE, de Vries AA, Ypey DL, van der Wall EE, Schalij MJ. Human adult bone marrow mesenchymal stem cells repair experimental conduction block in rat cardiomyocyte cultures. Journal of the American College of Cardiology. 2005;46:1943-1952

20. van Veen TA, de Bakker JM, van der Heyden MA. Mesenchymal stem cells repair conduction block. Journal of the American College of Cardiology. 2006;48:219-220; author reply 220

21. Bunch TJ, Mahapatra S, Bruce GK, Johnson SB, Miller DV, Horne BD, Wang XL, Lee HC, Caplice NM, Packer DL. Impact of transforming growth factorbeta1 on atrioventricular node conduction modification by injected autologous fibroblasts in the canine heart. Circulation. 2006;113:2485-2494

22. Kwaku KF. Cell therapy for rate control in atrial fibrillation: A new approach to an old problem. Circulation. 2006;113:2474-2476

23. Cavallini M. Autologous fibroblasts to treat deep and complicated leg ulcers in diabetic patients. Wound Repair Regen. 2007;15:35-38

24. Karchilaki I, Topakas G, Castana O, Sotiriou P, Michelakis D, Alexakis D, Giokas CS. The use of cultured autologous fibroblasts in burn wounds healing process. Burns. 2007;33:791-792

25. Keller G, Sebastian J, Lacombe U, Toft K, Lask G, Revazova E. Safety of injectable autologous human fibroblasts. Bulletin of experimental biology and medicine. 2000;130:786-789

26. Lamme EN, Van Leeuwen RT, Brandsma K, Van Marle J, Middelkoop E. Higher numbers of autologous fibroblasts in an artificial dermal substitute improve tissue regeneration and modulate scar tissue formation. The Journal of pathology. 2000;190:595-603

27. Wong T, McGrath JA, Navsaria H. The role of fibroblasts in tissue engineering and regeneration. The British journal of dermatology. 2007;156:1149-1155

28. Gaudesius G, Miragoli M, Thomas SP, Rohr S. Coupling of cardiac electrical activity over extended distances by fibroblasts of cardiac origin. Circulation research. 2003;93:421-428

29. Kizana E, Ginn SL, Allen DG, Ross DL, Alexander IE. Fibroblasts can be genetically modified to produce excitable cells capable of electrical coupling. Circulation. 2005;111:394-398 


\section{FIGURE LEGENDS:}

Figure 1: Three- dimensional mapping of right atrium with CARTO 4.0 mapping system. His bundle (orange dot) and CS ostium (pink dot) was marked on the map. Injections were performed along the slow and fast pathways around peri-nodal region (red dots).

Figure 2: RA septum visualization during necropsy in one animal. The dotted lines represent the histologic sections - A1, A2 and A3 were submitted to formalin fixation for 24 hours before embedding in paraffin; sections A2, B2 and C2 were frozen after use of fixation and sections A3, B3 and C3 were frozen without fixative. F. Ovalis = fossa ovalis; C.S. ostium = coronary sinus ostium.

Figure 3: Pig autologous skin fibroblasts in culture Panel A: Pig ADF culture at 2 days, 100X magnification. Panel B: Pig ADF culture at 28 days, 100X magnification.

Figure 4: PR interval on real-time ECG during 28 days of observation period

Figure 5: Presence of second degree AV block during real-time ECG monitoring in one animal at 2 days after $\mathrm{ADF}$ injections

Figure 6: Right atrium histology. A, Site of injection stained with H\&E. Arrows show sites of injection (4X); B, Section shown in panel A under 10X magnification; C, Site of injection stained with Masson Verhoeff. Arrows show the clusters of cells and D, shows the same area as panel $\mathrm{C}$ under 10X magnification.

Figure 7: Identification of ADF labeled with CM-DiI (A) and nuclei counterstaining with DAPI (B) 28 days after injection. The white arrows represent the edge of a site of the exact same field. 


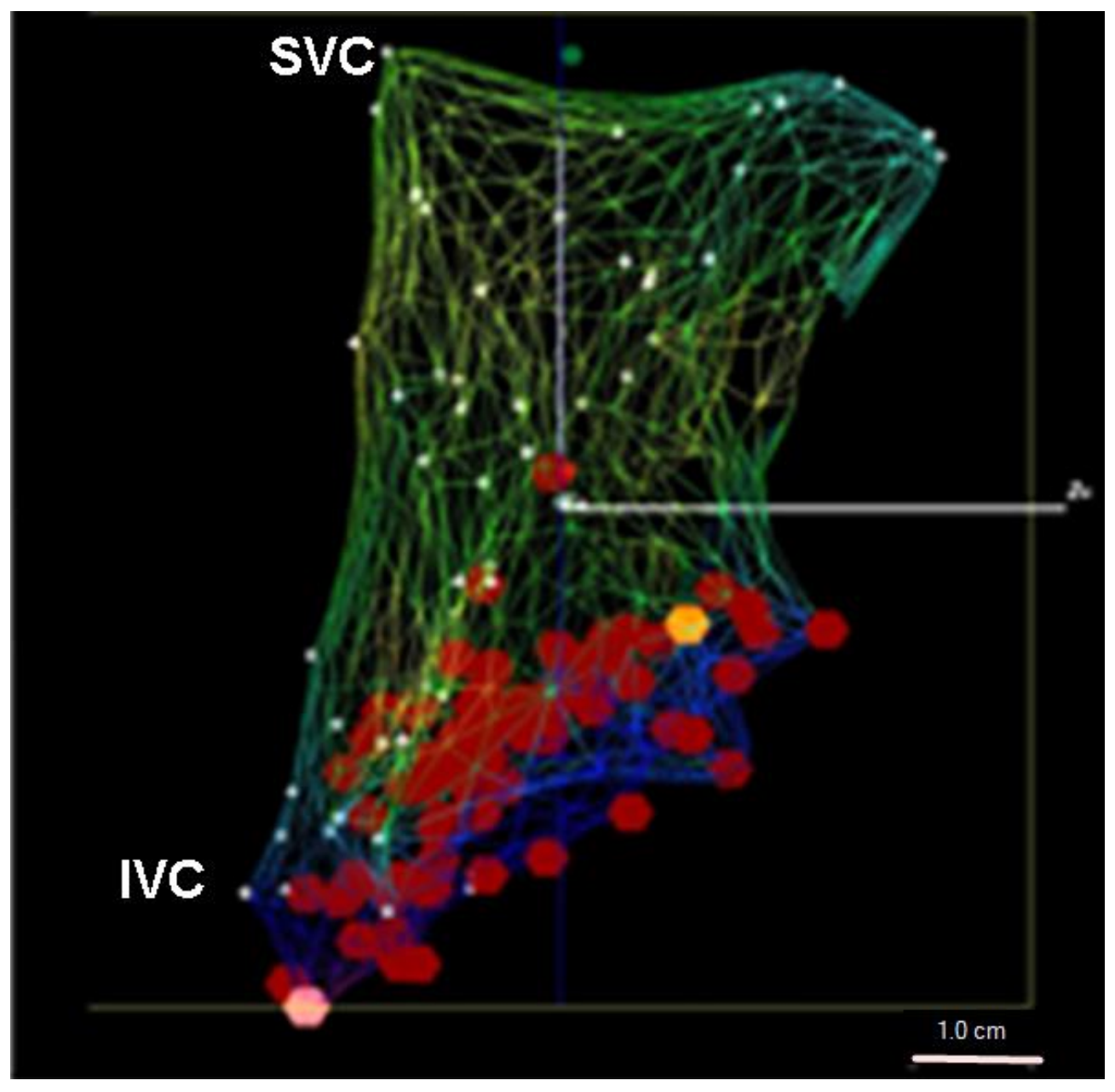

Figure 1 


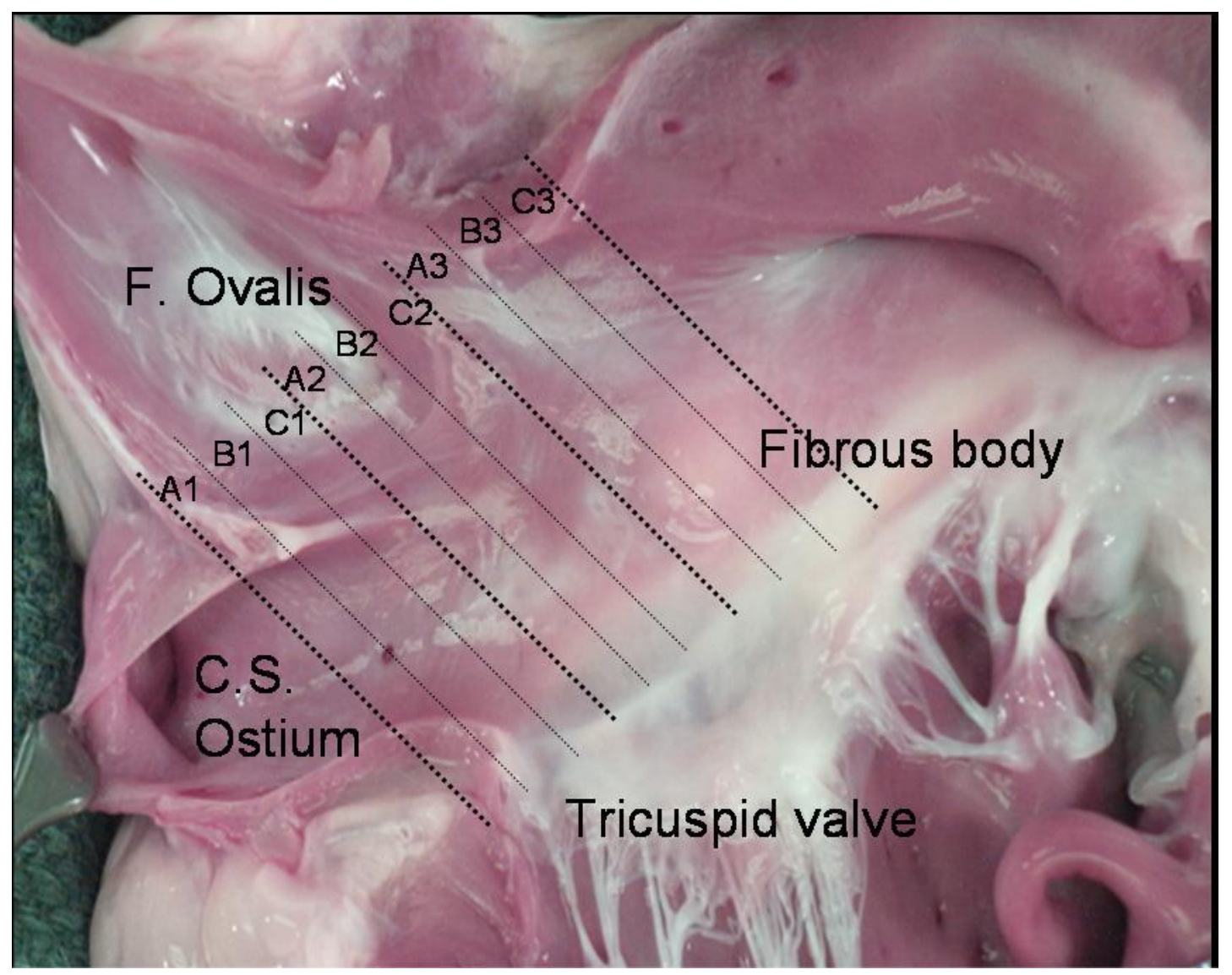

Figure 2 

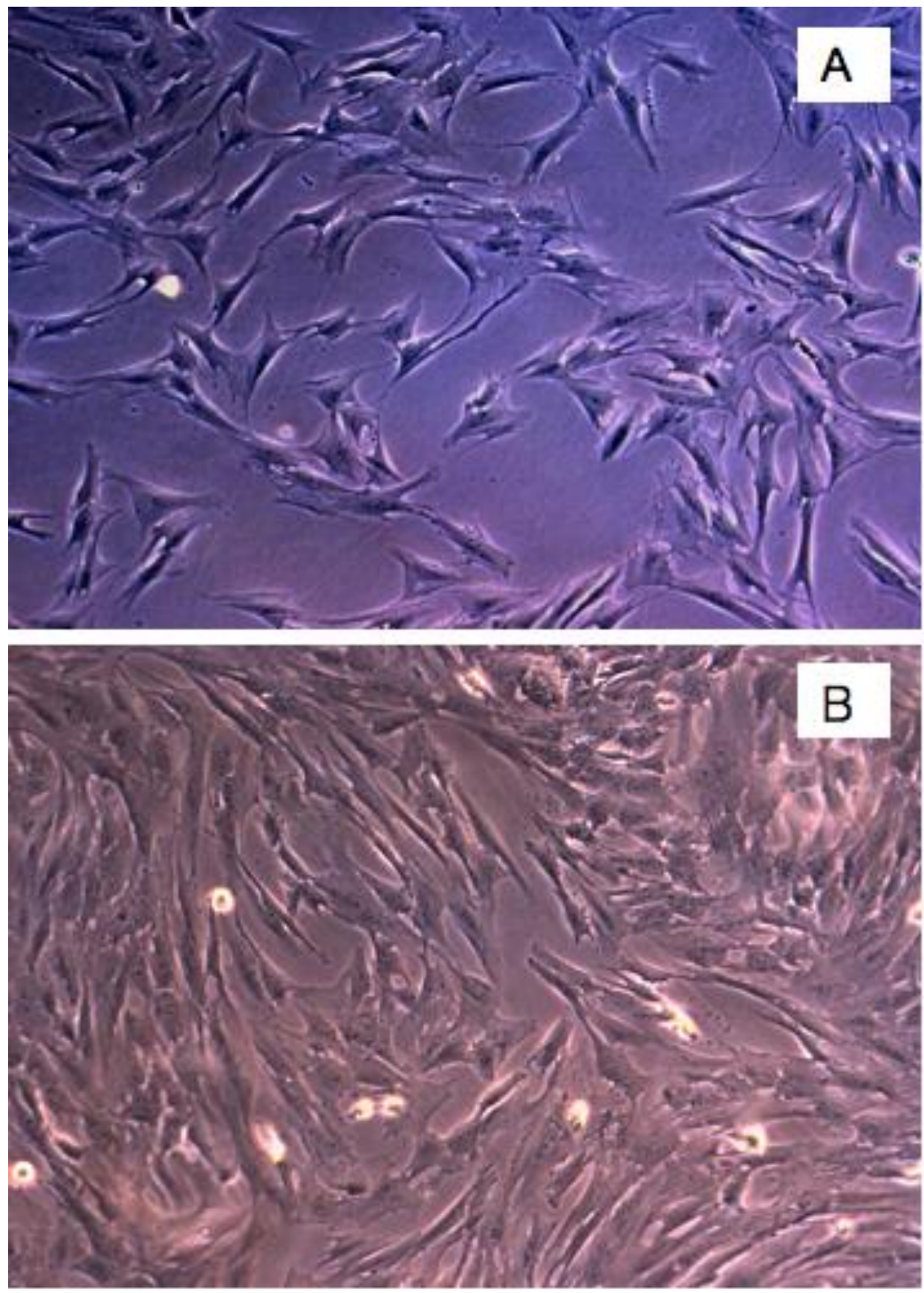

Figure 3 


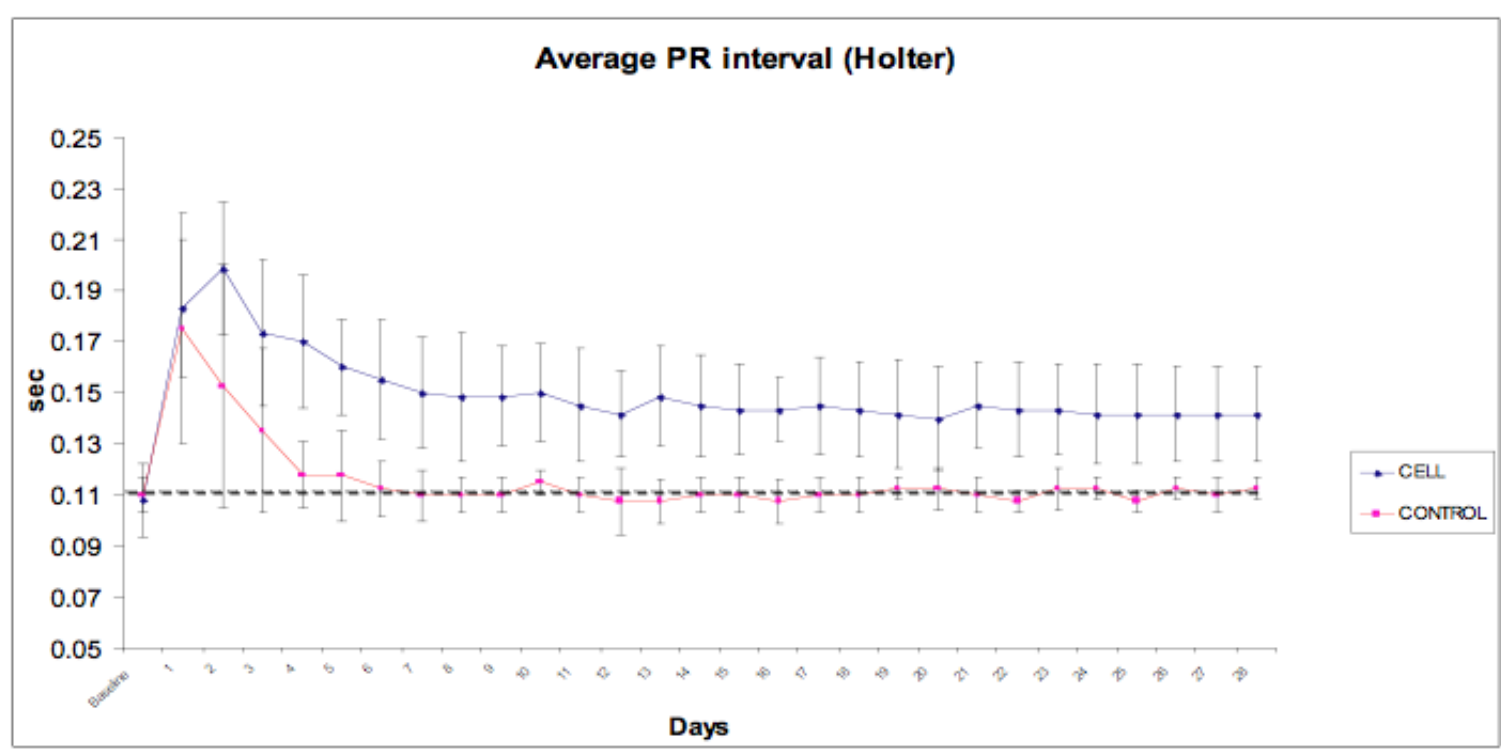

Figure 4

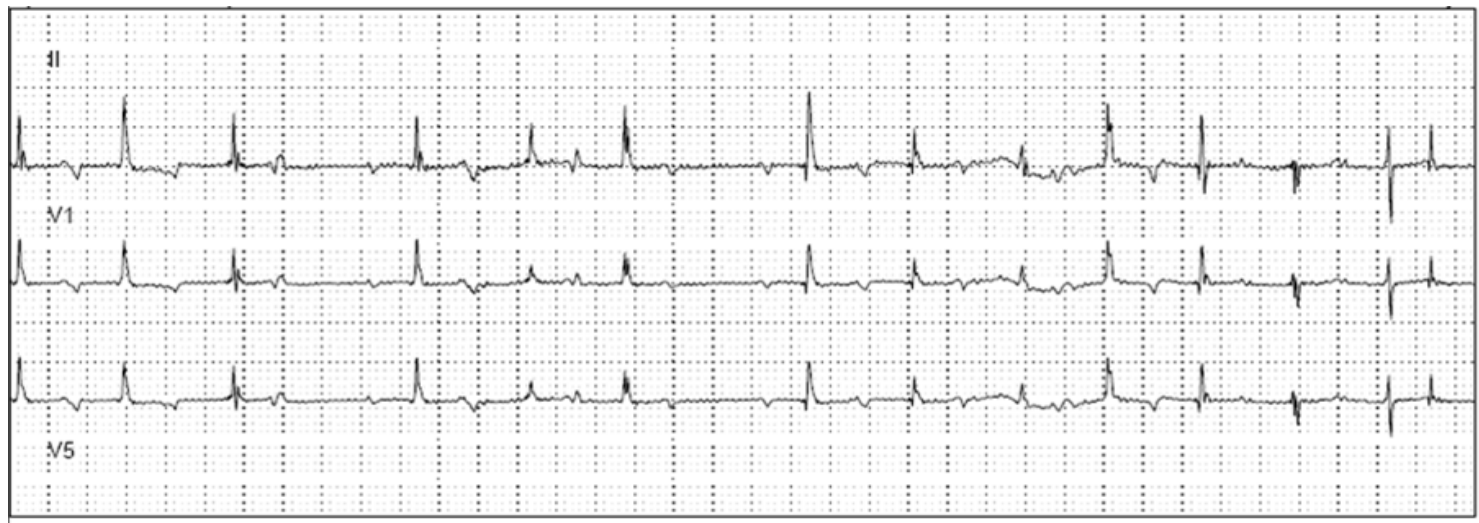

Figure 5 

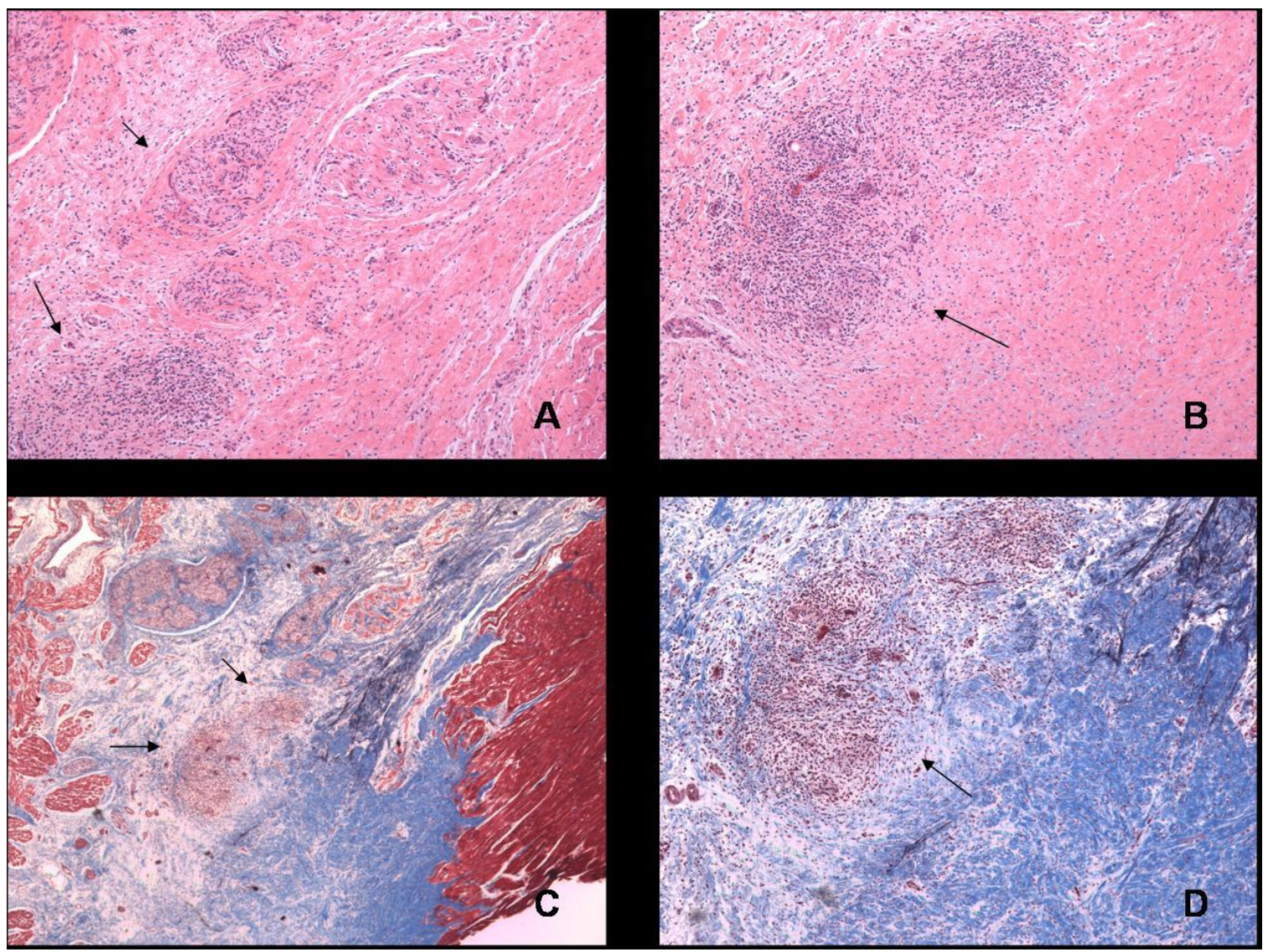

Figure 6

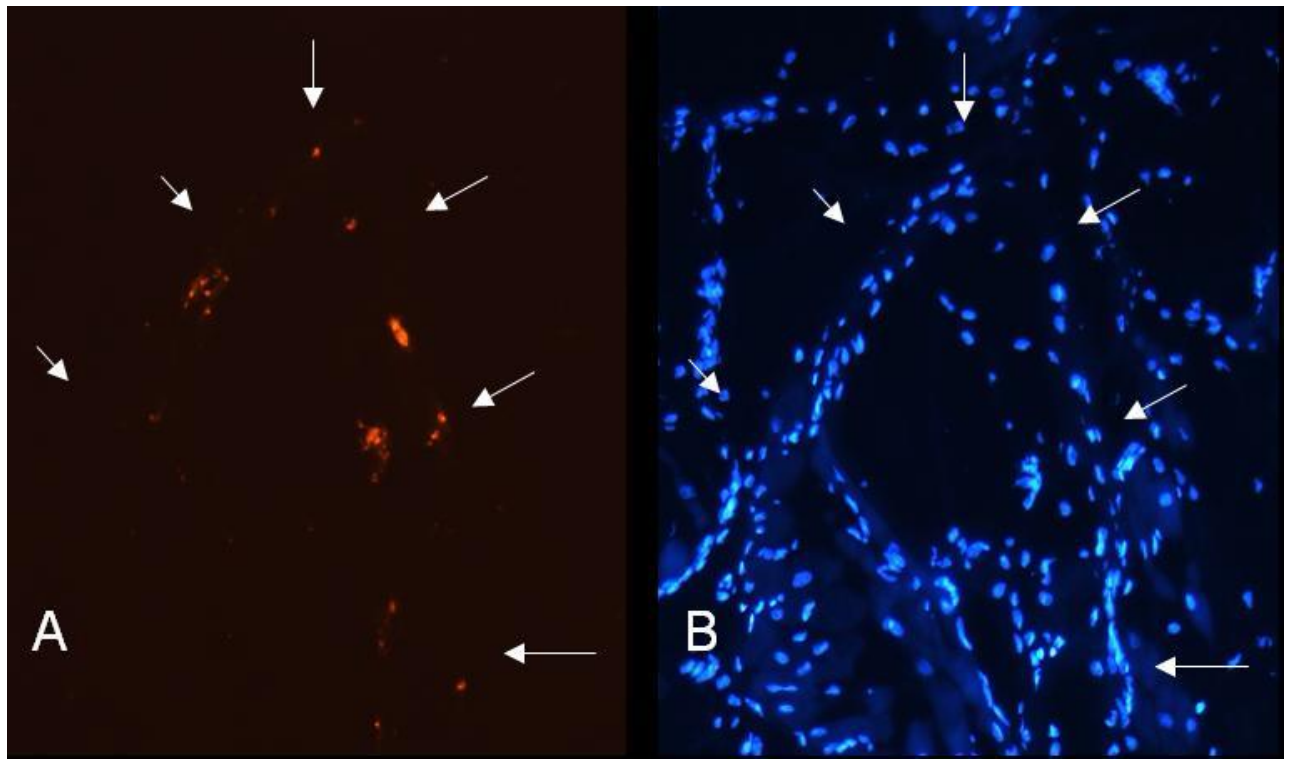

Figure 7 
Table 1. Basic interval measurements at baseline, post injection and at follow-up, expressed in miliseconds

\begin{tabular}{|l|c|c|c|c|c|c|c|c|}
\hline & \multicolumn{4}{|c|}{ ADF treated } & \multicolumn{4}{c|}{ Control } \\
\hline & Baseline & $\begin{array}{c}\text { Post } \\
\text { injection }\end{array}$ & 28 -day & $\begin{array}{c}p \\
\text { value }\end{array}$ & Baseline & $\begin{array}{c}\text { Post } \\
\text { Injection }\end{array}$ & 28 -day & $p$ value \\
\hline PR & $113 \pm 14$ & $163 \pm 17$ & $130 \pm 13$ & $0.04^{*}$ & $113 \pm 14$ & 146 & $124 \pm 12$ & $0.16^{*}$ \\
\hline AH & $80 \pm 7$ & $113 \pm 18$ & $92 \pm 13$ & $0.02^{*}$ & $75 \pm 9$ & $100 \pm 25$ & $76 \pm 8$ & $0.83^{*}$ \\
\hline HV & $34 \pm 3$ & $33 \pm 2$ & $33 \pm 1$ & $0.37^{* *}$ & $31 \pm 4$ & $32 \pm 2$ & $32 \pm 4$ & $0.47^{* *}$ \\
\hline
\end{tabular}

*Statistical comparison between 28-day and baseline

**Statistical comparison between baseline, post injection and 28-day follow-up

Table 2. AH interval measurements, expressed in miliseconds; and at pacing cycle length of 400,500 and $600 \mathrm{~ms}$

\begin{tabular}{|l|c|c|c|c|c|c|}
\hline & \multicolumn{3}{|c|}{ ADF treated } & \multicolumn{3}{c|}{ Control } \\
\hline & Baseline & 28 -day & $p$ value & Baseline & 28-day & $p$ value \\
\hline $\mathbf{4 0 0} \mathbf{~ m s}$ & $91 \pm 9$ & $102 \pm 13$ & $<0.01$ & $87 \pm 14$ & $88 \pm 12$ & 0.47 \\
\hline $\mathbf{5 0 0} \mathbf{~ m s}$ & $84 \pm 9$ & $96 \pm 15$ & 0.02 & $85 \pm 15$ & $82 \pm 9$ & 0.83 \\
\hline $\mathbf{6 0 0} \mathbf{~ m s}$ & $82 \pm 8$ & $93 \pm 16$ & 0.04 & $81 \pm 15$ & $78 \pm 10$ & 0.61 \\
\hline
\end{tabular}

